\title{
The association between body mass index and foot ulcer among patients with diabetes mellitus, Wad Medani, Sudan
}

\author{
Abeer AbdElrahman Elnour Eltilib \\ Assistant Professor of Family Medicine. \\ Faculty of Medicine, University of Gezira, \\ University City, Wad Medani, Gezira \\ State, Sudan
}

Correspondence:

Abeer AbdEIrahman Elnour Eltilib.

Abeert17@yahoo.com

Submitted: April 2021

Accepted: September 2021

Published: November 2021
Citation: Eltilib. The association between body mass index and foot ulcer among patients with diabetes mellitus, Wad Medani, Sudan. South Sudan Medical Journal 2021;14(4):122-126 (C) 2021 The Author (s) License: This is an open access article under CC BY-NC DOI: https:// dx.doi.org/10.4314/ssmj.v14i4.4

\begin{abstract}
Introduction: Globally about 463 million people are living with diabetes mellitus (DM) which is estimated to rise to 700 million by $2045 ; 80 \%$ are in middle and low-income countries. Recent studies have shown that body mass index (BMI) was one of the significant predictors, along with nephropathy and retinopathy, of diabetic foot ulcers (DFU).
\end{abstract}

Objective: To assess the association between BMI and DFU in Wad Medani town, Gezira state, Sudan.

Method: The study was based on primary data obtained via a cross sectional random sample of 400 patients with DM presenting at Aldarga Diabetic Centre in Wad Medani. The data collection tool was a structured questionnaire designed in English and translated into Arabic for the field survey. Data were analysed with SPSS version 20, using frequency tables and chi-square tests.

Results: Of the 400 participants, 208 were diagnosed with foot ulcer. There was a statistically significant association between BMI and DFU. A total of 134 (56\%) of the 239 overweight patients had diabetic foot ulcers compared to $74(46 \%)$ of the 161 who were not overweight $(\mathrm{p}=0.04)$.

Conclusion: The result suggests a significant association between BMI and DFU at our Diabetic Centre.

Keywords: diabetes, diabetic foot ulcer, body mass index, Gezira, Sudan

\section{Introduction}

Globally about 463 million people are living with diabetes mellitus (DM) and $80 \%$ are in middle and low-income countries. The International Diabetes Federation has estimated that the number of diabetes patients will rise to 700 million by 2045 . Almost half of adult type- 2 diabetes patients are unaware they have this disease and 185.8 million undiagnosed diabetics are in middle-income countries. ${ }^{[1]}$ Worldwide every 30 seconds, a lower limb is lost because of diabetes. The incidence of DFU amongst those with DM is 2\% (9.26 million) but the risk of recurrence for those with a history of DFU increases to $17-60 \%$ over the following three years. ${ }^{[2]}$

The prevalence of DM is expected to increase alarmingly in Africa. It is estimated that around 20 million Africans are now living with DM presenting a serious challenge for health systems now and in the future. A study in urban populations of the River Nile State, north Sudan, gave a prevalence of DM of 19.1\%; a high proportion of the patients were undiagnosed. ${ }^{[3]}$

Diabetic foot disease in Africa is also a growing problem and is associated with a high mortality. A meta-analysis reported data from 19 African countries on 56,173 diabetic patients with a prevalence of foot ulcers of $13 \%$, which increased over time, especially since 2001 . Approximately $15 \%$ of patients with foot lesions 
underwent major amputation and $14.2 \%$ died in hospital. ${ }^{[4]}$ In a 2017 study in Khartoum the occurrence of DFU was $18.1 \%{ }^{[5]}$

A study of DM patients in Ethiopia ${ }^{[6]}$ showed a relatively high incidence of DFU (4 per 100 person-years). A high body mass index (BMI) was one of the significant predictors, along with nephropathy and retinopathy. However, a meta-analysis in $2017^{[7]}$ concluded that lower BMI was associated with higher risk of DFU.

Although, as yet, few studies have investigated its global epidemiology, diabetic foot is a severe public health issue and close monitoring of patients is essential to reduce DFU.

This study, as far as we know, may be the first to estimate the association between BMI and DFU among patients with DM, in Wad Medani, Sudan.

\section{Definitions}

- The International Working Group on the Diabetic Foot has defined the diabetic foot as "infection, ulceration, or destruction of tissues of the foot of a person with currently or previously diagnosed diabetes mellitus, usually accompanied by neuropathy and/or peripheral arterial disease (PAD) in the lower extremity."

- Diabetic foot ulcers are non-traumatic lesions of the skin on the foot distal to the malleoli.

- Body Mass Index (BMI) = body weight $(\mathrm{kg})$ divided by the height $(\mathrm{m} 2)$. In adults BMI of $<18.5=$ underweight, $18.5-<25=$ normal range and $\geq 25.0=$ overweight.

- Diagnostic criteria for diabetes mellitus: Random plasma glucose $\geq 200 \mathrm{mg} / \mathrm{dL}(\geq 11.1 \mathrm{mmol} / \mathrm{L})$ or 1 fasting plasma glucose value of $\geq 126 \mathrm{mg} / \mathrm{dL}$ ( $\geq 7.0$ $\mathrm{mmol} / \mathrm{L}$ ) or 2 -h. Oral glucose (100grams) tolerance test (GTT) value in venous plasma $\geq 200 \mathrm{mg} / \mathrm{dL}$ $(\geq 11.1 \mathrm{mmol} / \mathrm{L})$ glycated haemoglobin (HbAlc) $\geq 6.5 \%$ ( $\geq 48 \mathrm{mmol} / \mathrm{molHb}$ ).

\section{Ethical Aspects}

Ethical approval for the study was given by the Director of Health Affairs, Wad Medani. Permissions for data collection were obtained from the centre managers, and oral informed consent from the study participants after assuring them of the confidentiality of their data.

\section{Method}

This was a cross-sectional study among patients needing specialized care attending for follow-up at Aldarga Diabetic Health Centre in Wad Medani Town, Gezira State, Sudan from September to December 2020. The Centre is in the north of Wad Medani town, 186 kilometres south of Khartoum. It opened in 2007 as a specialized Diabetic
Table 1. Demographic characteristics

\begin{tabular}{|c|c|c|}
\hline Characteristics & Characteristics & n (\%) \\
\hline \multirow[t]{6}{*}{ Age range (years) } & $30-39$ & $25(6.2)$ \\
\hline & $40-49$ & $59(14.8)$ \\
\hline & $50-59$ & $103(25.8)$ \\
\hline & $60-69$ & $105(26.2)$ \\
\hline & $70-79$ & $90(22.5)$ \\
\hline & $80-89$ & $18(4.5)$ \\
\hline \multirow[t]{2}{*}{ Sex } & Male & $222(55.5)$ \\
\hline & Female & $178(44.5)$ \\
\hline \multirow[t]{2}{*}{ Residence } & Town & $225(56)$ \\
\hline & Village & $175(44)$ \\
\hline \multirow[t]{2}{*}{ Type of family } & Nuclear & $168(42)$ \\
\hline & Extended & $232(58)$ \\
\hline \multirow[t]{3}{*}{ Income level } & Low & $134(33.5)$ \\
\hline & Medium & $232(58)$ \\
\hline & High & $34(8.5)$ \\
\hline \multirow[t]{4}{*}{ Marital status } & Single & $27(6.8)$ \\
\hline & Married & $277(69.2)$ \\
\hline & Widow & $72(18)$ \\
\hline & Divorced & $24(6)$ \\
\hline \multirow[t]{7}{*}{$\begin{array}{l}\text { Type of work of } \\
\text { respondent }\end{array}$} & $\begin{array}{l}\text { Professional / } \\
\text { Business }\end{array}$ & $64(16)$ \\
\hline & $\begin{array}{l}\text { Contracted } \\
\text { Employee }\end{array}$ & $35(8.8)$ \\
\hline & Other Employee & $15(3.7)$ \\
\hline & Farmer & $20(5)$ \\
\hline & Housewife & 54 (13.5) \\
\hline & Other & $60(15)$ \\
\hline & Unemployed & $152(38)$ \\
\hline \multirow[t]{5}{*}{ Educational level } & Illiterate & $34(8.5)$ \\
\hline & Khalwa/Madrasa & 77 (19.3) \\
\hline & Basic & $159(39.8)$ \\
\hline & Secondary & $81(20.2)$ \\
\hline & $\begin{array}{l}\text { University/ } \\
\text { Postgraduate }\end{array}$ & $49(12.2)$ \\
\hline Total & & 400 (100) \\
\hline
\end{tabular}

Centre for the Central Region. So, the sampled population was not representative of the general population.

\section{Sample size and sampling}

We calculated that a sample size of 400 would be adequate to show a difference in prevalence of DFU between low/normal BMI and high BMI patients. The number of diabetic patients who reported to the Centre 


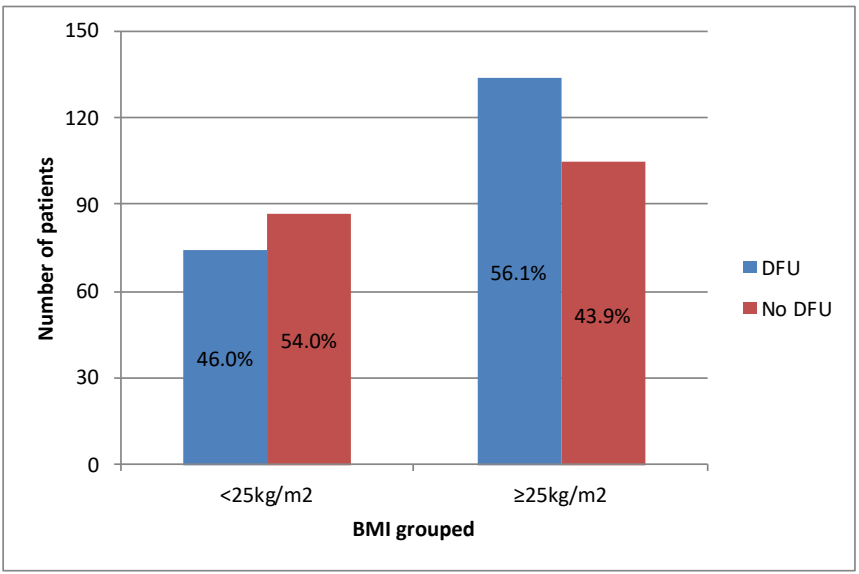

Figure 1. Relationship between BMI and DFU in 2020 was 40,507 . First, we calculated the systematic sampling interval factor by dividing the total number of diabetic patients during the data collection period (November-December 2020) by the sample size i.e., N/ $\mathrm{n}=1823 / 400=4.55 \cong 5$. The sample unit number 5 was selected.

Then, patients presenting to the centre during November and December 2020, were randomly selected, separately by sex, until we achieved our desired sample size of 400 . Fewer patients than usual attended during these months due to the COVID-19 pandemic, so our sample may not be completely representative of all the patients attending the Centre. All the selected patients agreed to take part in the study.

Table 2. Diabetic specific variables for further research

\begin{tabular}{|c|c|c|c|c|}
\hline \multirow[t]{2}{*}{ Variable } & \multirow[t]{2}{*}{ Response } & \multicolumn{3}{|c|}{ DFU } \\
\hline & & Yes & No & Total \\
\hline \multirow[t]{2}{*}{ Diabetic in the family } & Yes & 108 & 86 & 194 \\
\hline & No & 100 & 106 & 206 \\
\hline \multirow[t]{2}{*}{ Knowledge of caring for foot wound } & Yes & 191 & 179 & 370 \\
\hline & No & 17 & 13 & 30 \\
\hline \multirow[t]{2}{*}{ Wearing diabetic shoes } & Yes & 136 & 102 & 238 \\
\hline & No & 72 & 90 & 162 \\
\hline \multirow[t]{2}{*}{ Other wounds } & Yes & 52 & 44 & 96 \\
\hline & No & 156 & 148 & 304 \\
\hline \multirow[t]{2}{*}{ Feeling better since going to doctor } & Yes & 195 & 178 & 373 \\
\hline & No & 13 & 14 & 27 \\
\hline \multirow[t]{2}{*}{ Having leg or foot disability } & Yes & 53 & 79 & 132 \\
\hline & No & 155 & 113 & 268 \\
\hline \multirow[t]{3}{*}{ Type of disability } & Functional & 24 & 42 & 66 \\
\hline & Muscle & 28 & 35 & 63 \\
\hline & Wound & 1 & 2 & 3 \\
\hline \multirow[t]{3}{*}{ Duration of disability } & $<12$ months & 9 & 17 & 26 \\
\hline & $1-<5$ years & 24 & 21 & 45 \\
\hline & $\geq 5$, years & 20 & 41 & 61 \\
\hline \multirow{2}{*}{$\begin{array}{l}\text { Disability effect (e.g., psychological impact, } \\
\text { financial impact) }\end{array}$} & Yes & 23 & 46 & 69 \\
\hline & No & 30 & 33 & 63 \\
\hline \multirow[t]{3}{*}{ Foot or toe amputation } & One & 14 & 11 & 25 \\
\hline & More than one & 36 & 54 & 90 \\
\hline & No amputation & 158 & 127 & 285 \\
\hline \multirow[t]{2}{*}{ Foot amputation } & Yes & 18 & 33 & 51 \\
\hline & No & 190 & 159 & 349 \\
\hline Total & & 208 & 192 & 400 \\
\hline
\end{tabular}




\section{Data collection}

Data were collected by field data collectors using a structured questionnaire, mainly adapted from World Health Organization and other publications, written in English and then translated into Arabic. It was pretested on $8 \%$ of the total sample size and internal consistency measured under reliability by calculating Cronbach's Alpha coefficient. (The value of Cronbach's Alpha coefficient was greater than 90\%).

Four hundred participants were recruited by the field data collection team, which consisted of the principal researcher, and 21 field data collectors who were paramedics working in the Centre and trained for 10 days on data collection methods and the interview/observation methodology. The training focused particularly on the anthropometric data collection. The presence or not of DFU was reported by the patient, and it was not recorded whether or not this was a first occurrence or a reoccurrence. Quality of collected data was checked by three well-trained paramedical staff who entered the data in SPSS program.

\section{Population}

The participants were selected from all the adult $(\geq 18$ years) diabetic patients at the follow-up clinic at Aldarga Diabetic Centre, but those who were seriously ill, gestational diabetic, diabetic patients who had traumatic ulcer, or clinically suspected of having Charcot foot were excluded. Data were coded and entered into a computer using two versions (24.0/25.0) of the Statistical Package for Social Sciences (SPSS) for Windows.

\section{Results}

Table 1 shows that of the 400 sampled, $55 \%$ were males and $45 \%$ were females, $58 \%$ lived in extended families and $56 \%$ lived in towns. Income was based on participants' reports; $9 \%$ reported having a high income, $58 \%$ reported a medium income, and $33 \%$ a low income and showing that diabetic patients reporting to Aldarga Centre come mostly from families having a medium to low income.

The relationship between grouped BMI and foot ulcer was evaluated using a chi-squared test and is shown in Figure 1. Overweight patients were at significantly greater risk of DFU ( $\mathrm{p}=0.04$, relative risk 1.22).

We also collected data on other potentially relevant variables, and this information, without statistical analysis, is presented in Table 2 .

The factors in Table 2 were not included at the outset as predictor variables. Although they have been analysed statistically, and some have p-values equal to or less than 0.05 , great caution is needed to interpret them as there is a 1 in 20 chance that any such variable will, simply by chance, reach "significance." Further research is therefore needed.

\section{Discussion}

Our sample may not have been representative of all the diabetic patients attending the Aldarga Diabetic Health Centre in Gezira, especially as data were collected during the COVID-19 pandemic. We chose to treat BMI as a two-level categorical variable, but we may have obtained a different result treating it as a continuous variable. We did not examine whether BMI was independently associated with DFU, or if other variables, such as glucose levels or diabetes duration could explain the association. Further analysis of our data is needed.

We are not aware of a study looking at the association between BMI and DFU in Gezira state, Sudan. Our findings are similar to those previously reported ${ }^{[8,5,9,10]}$ showing a strong association between a high BMI and the development of DFU. It might be that the higher the BMI the greater chance of hyperlipidaemia and vascular disease which, in turn, decreases blood supply to the lower extremities. Also, higher BMI is likely to lead to greater glucose intolerance and more severe DM with increasing vascular complications.

Although a 2017 meta-analysis study ${ }^{[7]}$ that noted that "the contribution of obesity to the risk of diabetic foot ulceration is inconclusive," research by Zubair et al in India showed a positive correlation between ulcer duration and BMI, and amputation rate and BMI. ${ }^{[11]}$

Although the variables in Table 2 need further analysis the data do suggest an association between duration of diabetes and DFU (as shown in a paper from Cameroon ${ }^{[12]}$ and dyslipidaemia and DFU which is similar to publications from Ethiopia, Saudi Arabia and India. ${ }^{[13,14 i, 15]}$

A variety of foot abnormalities and disabilities appeared to have differing effects for our patients (e.g., health and economic impact) so as family doctors our responsibilities towards our society are to detect the above risk factors for DFU early and try to ameliorate them.

\section{Limitation of the study}

There might be recall bias or reporting bias regarding the contributing factors, such as alcohol use or smoking frequency. Further, the cross-sectional nature of the study does not confirm the definitive cause and effect relationship.

\section{Conclusion}

DFU is a serious problem in Gezira and its occurrence is increasing. Encouraging overweight patients to reduce their BMI should contribute to reducing the risk of DFU.

\section{Acknowledgement}

The authors thank the Aldarga Health Centre for its co-operation and the diabetic patients who participated willingly in the study. 
Funding: This research received no specific funding.

References

1. Saeedi P, Salpea P, Karuranga S, et al. Mortality attributable to diabetes in 20-79 years old adults, 2019 estimates: Results from the International Diabetes Federation Diabetes Atlas, 9th edition. Diabetes Res Clin Pract. 2020;162:108086.. https://doi.org/10.1016/j.diabres.2020.108086

2. Dubský M, Jirkovská A, Bem R, et al. Risk factors for recurrence of diabetic foot ulcers: prospective follow-up analysis in the Eurodiale subgroup. Int Wound J. 2013;10(5):555-561. https://doi. org/10.1111/j.1742-481X.2012.01022.x

3. Elmadhoun WM, Noor SK, Ibrahim AA, Bushara SO, Ahmed MH. Prevalence of diabetes mellitus and its risk factors in urban communities of north Sudan: Population-based study. J Diabetes. 2016 Nov;8(6):839-846. https://doi. org/10.1111/1753-0407.12364 . Epub 2016 Feb 24. PMID: 26663723.

4. Rigato M, Pizzol D, Tiago A, Putoto G, Avogaro A, Fadini GP. Characteristics, prevalence, and outcomes of diabetic foot ulcers in Africa. A systemic review and meta-analysis. Diabetes Res Clin Pract. 2018;142:63-73. https://doi/ org/10.1016/j.diabres .2018.05.016

5. Almobarak AO, Awadalla H, Osman M, Ahmed $\mathrm{MH}$. Prevalence of diabetic foot ulceration and associated risk factors: an old and still major public health problem in Khartoum, Sudan? Ann Transl Med. 2017 Sep;5(17):340. https:// doi.org/10.21037/atm .2017.07.01. PMID: 28936434; PMCID: PMC5599292.

6. Adem AM, Andargie AA, Teshale AB, Wolde HF. Incidence of Diabetic Foot Ulcer and Its Predictors Among Diabetes Mellitus Patients at Felege Hiwot Referral Hospital, Bahir Dar, Northwest Ethiopia: A Retrospective Follow-Up Study. Diabetes Metab Syndr Obes. 2020;13:3703-3711. Published 2020 Oct 14. https://doi.org/10.2147/ DMSO.S280152

7. Zhang $P$, Lu J, Jing $Y$, Tang S, Zhu D, Bi Y. Global epidemiology of diabetic foot ulceration: a systematic review and meta-analysis $\dagger$. Ann Med. 2017;49(2):106-116. https://doi.org/10.1080/07 853890.2016 .1231932
8. Pinzur M, Freeland R, Juknelis D. The association between body mass index and foot disorders in diabetic patients. Foot Ankle Int. 2005;26(5):375-377. https://doi. org/10.1177/107110070502600506

9. Sohn Min-Woong, Budiman-Mak E, Lee T, Oh E, Stuck R. Significant J-shaped association between body mass index (BMI) and diabetic foot ulcers. Diabetes/metabolism research and reviews 2011: 27:402-9. 10.1002/dmrr.1193.

10. Kim TG, Moon SY, Park MS, et al. Factors Affecting Length of Hospital Stay and Mortality in Infected Diabetic Foot Ulcers Undergoing Surgical Drainage without Major Amputation. J Korean Med Sci. 2016;31(1):120-124. https:// doi.org/10.3346/jkms.2016.31.1.120

11. Zubair M, Malik A, Ahmad J. Correlation of $\mathrm{HbA} 1 \mathrm{c}$ and S. creatinine along with microbiological profiling of infected ulcers; cases of diabetic patients. Diabetes Metab Syndr. 2019;13(1):3034. https://doi.org/10.1016/j.dsx.2018.08.011

12. Tindong $M$, Palle JN, Nebongo $D$, et al. Prevalence, Clinical Presentation, and Factors Associated with Diabetic Foot Ulcer in Two Regional Hospitals in Cameroon. Int J Low Extrem Wounds. 2018;17(1):42-47. https://doi. org/10.1177/1534734618764252

13. Haile K, Timerga A. Dyslipidemia and Its Associated Risk Factors Among Adult Type-2 Diabetic Patients at Jimma University Medical Center, Jimma, Southwest Ethiopia. Diabetes Metab Syndr Obes. 2020;13:4589-4597. https:// doi.org/10.2147/DMSO.S283171

14. Abdulghani HM, AlRajeh AS, AlSalman BH, et al. Prevalence of diabetic comorbidities and knowledge and practices of foot care among diabetic patients: a cross-sectional study. Diabetes Metab Syndr Obes. 2018;11:417-425. https://doi. org/10.2147/DMSO.S171526

15. Saxena T, Malhotra M, Yadav RK, Gupta SK. Prevalence and association of co-morbidities in diabetic patients along with prescription patterns in Delhi-NCT, India. Diabetes Metab Syndr. 2019;13(2):1209-1212. https://doi. org/10.1016/j.dsx.2019.01.007 